\title{
Trauma por queimaduras: uma análise das internações hospitalares no Brasil
}

\author{
Burn trauma: an analysis of hospital hospitalizations in Brazil
}

Trauma por quemaduras: un análisis de hospitalizaciones hospitalarias en Brasil

Rafael Campos Oliveira ${ }^{1}$, Kalyne Naves Guimarães Borges ${ }^{1 *}$, Carolina Braga dos Santos Azevedo ${ }^{1}$,

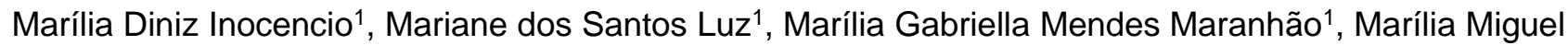
de Lucena ${ }^{1}$, Marina Borges de Paula ${ }^{1}$, Rafaela Silva Oliveira ${ }^{1}$, Luiz Gaspar Machado Pellizzer ${ }^{1}$.

\section{RESUMO}

Objetivo: Analisar o perfil epidemiológico dos casos notificados de queimaduras no Brasil, no período entre 2015 a 2019. Métodos: Trata-se de um estudo epidemiológico descritivo-analítico, cujos dados foram obtidos por meio do preenchimento da ficha de notificação "Queimaduras e corrosões", disponível no Sistema de Informações Hospitalares do Sistema Único de Saúde (SIH-SUS), da Secretaria de Vigilância em Saúde (SVS), do Ministério da Saúde (MS). Foram calculadas as frequências de variáveis segundo o ano e região de notificação, o perfil das vítimas (sexo e faixa etária), e o caráter de atendimentos dos casos. Resultados: Obteve-se amostra de 127.190 casos referentes às notificações por queimaduras. No período analisado, o ano de 2019 obteve maior prevalência. As regiões Sudeste e Nordeste tiveram predomínio de notificações por queimaduras. O sexo masculino, a faixa etária entre 20 a 39 anos e o caráter de atendimento urgente foram os mais prevalentes. Conclusão: Ressalta-se a importância da ampliação de esforços em ações educativas que visam prevenir acidentes de queimaduras, principalmente àqueles grupos de maior risco.

Palavras-chave: Queimaduras, Epidemiologia, Unidade de queimados.

\section{ABSTRACT}

Objective: To analyze the epidemiological profile of notified cases of burns in Brazil, in the period between 2015 to 2019. Methods: This is a descriptive-analytical epidemiological study, whose data were obtained by completing the notification form "Burns and corrosions", Available in the SUS Hospital Information System of the Unified Health System (SIH-SUS), of the Health Surveillance Secretariat (SVS), of the Ministry of Health (MS). The frequencies of variables were calculated according to the year and region of notification, the profile of the victims (sex and age group), and the character of the cases attended. Results: A sample of 127.190 cases regarding burn notifications was obtained. In the period analyzed, 2019 was more prevalent. The Southeast and Northeast regions had a predominance of notifications for burns. The male gender, the age group between 20 to 39 years and the character of urgent care were the most prevalent. Conclusion: It stands out emphasize the importance of expanding efforts in educational actions aimed at preventing burn accidents, especially for those groups at greatest risk.

Keywords: Burns, Epidemiology, Burn units.

\section{RESUMEN}

Objetivo: Analizar el perfil epidemiológico de los casos notificados de quemaduras en Brasil, en el período de 2015 a 2019. Métodos: Se trata de un estudio epidemiológico descriptivo-analítico, cuyos datos se obtuvieron al completar el formulario de notificación "Quemaduras y corrosiones", Disponible en el Sistema de Información Hospitalaria del Sistema Único de Salud (SIH-SUS), de la Secretaría de Vigilancia en Salud (SVS), del Ministerio de Salud (MS). Se calcularon las frecuencias de las variables según el año y región de notificación, el perfil de las víctimas (sexo y grupo de edad) y el carácter de los casos atendidos. Resultados: Se obtuvo una muestra de 127.190 casos de notificaciones de quemaduras. En el período analizado, 2019 fue más prevalente, y las regiones Sudeste y Noreste tuvieron predominio de notificaciones por quemaduras. El género masculino, el grupo de edad entre 20 a 39 años y el carácter de atención urgente fueron los más prevalentes. Conclusión: Se enfatiza la importancia de expandir esfuerzos en acciones educativas que tengan como objetivo prevenir los accidentes por quemaduras, principalmente aquellos grupos de mayor riesgo.

Palabras clave: Quemaduras, Epidemiología, Unidades de quemados.

\footnotetext{
${ }^{1}$ Universidade de Rio Verde (UniRV), Aparecida de Goiânia - GO.

*E-mail: kalyne.naves@gmail.com
} 


\section{INTRODUÇÃO}

A queimadura é conceituada como uma lesão causada por um agente externo que pode ser originado por diversas fontes. O trauma resultante deste evento constitui um problema de saúde pública atemporal e persistente no Brasil. Além de ser um importante fator relacionado ao aumento de mortalidade por causas externas, ela acarreta diminuição na qualidade de vida de seus sobreviventes, sobretudo em virtude das sequelas que produz (MARINHO LP, et al., 2018).

A Organização Mundial da Saúde (OMS) afirma que anualmente cerca de 130 mil pessoas sofrem algum tipo de acidente por queimadura. No Brasil, ocorrem cerca de 100 mil notificações de casos de queimaduras por ano, com aproximadamente 3.000 mil pessoas que evoluem para o óbito após o trauma (BARCELLOS LG, et al., 2018). Estes dados evidenciam a necessidade de investimento constante por parte do sistema de saúde em ações de prevenção e manejo adequado das vítimas de queimaduras.

As queimaduras podem ser classificadas de acordo com a profundidade, a extensão e a gravidade da lesão. Quanto à profundidade, ela é classificada em primeiro grau quando acomete apenas a epiderme; em segundo grau quando abrange a epiderme e a derme; e em terceiro grau quando atinge todas as camadas dérmicas, podendo lesionar também tendões, músculos e ossos. A extensão da lesão é medida de acordo com a superfície corporal da pele queimada. A regra de Wallace, também conhecida como regra dos nove, é utilizada para determinar a extensão das lesões, através do cálculo da percentagem das regiões corporais lesionadas na queimadura.

Em relação à gravidade, são consideradas queimaduras graves as lesões com extensão maior que $20 \%$ em adultos ou maior que $10 \%$ em crianças; as originadas por fontes elétricas ou químicas; as que envolvem vítimas com mais de 65 anos ou menos que 3 anos de idade; e as que geram lesão inalatória ou lesões em regiões nobres do corpo, como em face e em pescoço (BRASIL, 2012; LOPES DR, et al., 2016).

Além disso, as queimaduras podem ser classificadas de acordo com o agente causal, podendo abranger os tipos elétrica, química, térmica, radiológica, solar, entre outros. Queimaduras elétricas e químicas estão associadas principalmente às atividades laborais que utilizam a eletricidade e determinadas substâncias químicas (CAMPOS ALS, et al., 2016).

Ainda, situações que envolvem o uso de álcool e substâncias explosivas, como em festas com o uso de fogueiras e fogos de artifícios, estão associadas a maior prevalência de acidentes por queimaduras térmicas (JUNIOR RAS, et al., 2016). Como já mencionado, as queimaduras químicas e elétricas são consideradas graves.

Quanto à epidemiologia, estudos indicam que na maioria das internações hospitalares as vítimas apresentam queimaduras de primeiro e segundo graus. A maioria dos casos resultam em lesões de aproximadamente 20 a $25 \%$ de extensão, sendo a face, os membros superiores e o tronco as principais regiões corporais atingidas. A fonte térmica é a principal causadora dos acidentes, principalmente pelo contato com água e líquidos em elevadas temperaturas. As queimaduras por agentes radioativos são as menos comuns (CRUZ BF, et al., 2012).

Em relação às vítimas de queimaduras, estima-se que os acidentes envolvam principalmente homens e crianças. Os acidentes com homens comumente estão relacionados às atividades ocupacionais, sobretudo quando ocorre a negligência do uso de equipamentos de proteção. Em crianças, há a prevalência de acidentes domésticos, com destaque para a faixa etária de 1 a 4 anos de idade.

Os casos de queimaduras que envolvem mulheres estão associados principalmente a acidentes com fogo, durante o preparo de alimentos (MALTA DC, et al., 2020). Em idosos, as queimaduras têm relação com as limitações físicas e menor capacidade reativa durante acidentes (JUNIOR RAS, et al., 2016).

A letalidade do trauma por queimaduras tem estreita relação com as complicações infecciosas das lesões. Ao destruir a barreira cutânea, as queimaduras geram propensão à invasão e crescimento bacteriano, o que, concomitantemente à imunossupressão causada pelo trauma, provoca risco elevado de evolução para sepse e, consequentemente, o óbito (CHAVES SCS, 2013). 
Os principais patógenos causadores da sepse em pacientes queimados são o Staphylococcus aureus e Staphylococcus coagulase negativo. Ademais, o uso de cateteres, a superfície corporal queimada maior que $30 \%$ e os acidentes com vítima do sexo feminino estão associados ao maior risco de sepse (COUTINHO JGV, et al., 2015).

O processo de reabilitação psicológica de pacientes queimados pode ser bastante complexo. As lesões, sobretudo aquelas em regiões corpóreas expostas, provocam diminuição da autoestima e da segurança, além de sintomas como sentimento de impotência e culpa pelo acidente ocorrido. Quanto mais extensa a superfície corpórea queimada, maiores serão as dificuldades de reabilitação destes pacientes, em âmbito psicoemocional. O estado de saúde mental anterior ao evento que repercute na queimadura e a capacidade de enfrentamento de situações inusitadas, estão intimamente relacionados neste processo de reabilitação psicológica (GONÇALVES N, et al., 2011).

Considerando isso, é possível perceber a complexidade dos traumas por queimaduras, já que este agravo à saúde pode envolver múltiplos fatores, como acidentes domésticos e laborais ou lesões autoprovocadas, além de não se limitar a apenas um gênero ou faixa etária. Com isso, nota-se a importância do Sistema de Informações Hospitalares do Sistema Único de Saúde (SIH-SUS), que permite a identificação do perfil epidemiológico das vítimas e o monitoramento dos índices de queimaduras a cada ano, através da notificação de casos que necessitam de suporte hospitalar.

Dessa forma, e considerando os impactos do trauma por queimaduras no Brasil, entende-se a relevância de se compreender o perfil epidemiológico e o grupo associado a maior risco para este evento, tendo em vista a importância de ações preventivas, voltadas sobretudo aos grupos mais expostos às queimaduras. Por meio do sistema de notificação, é possível identificar estes grupos de risco envolvidos em traumas por queimaduras.

O objetivo deste estudo foi analisar o perfil epidemiológico dos casos notificados de queimaduras no Brasil, no período entre 2015 a 2019, correlacionando as variáveis segundo o ano e região de notificação, o perfil das vítimas (sexo e faixa etária) e o caráter de atendimentos dos casos.

\section{MÉTODOS}

Trata-se de um estudo epidemiológico descritivo-analítico, cujos dados foram obtidos por meio do preenchimento da ficha de notificação "Queimaduras e corrosões", disponível no SIH-SUS, da Secretaria de Vigilância em Saúde (SVS), do Ministério da Saúde (MS).

Utilizou-se como amostra todos os casos de notificações de queimaduras no período entre 2015 a 2019 , no Brasil. Os dados foram coletados a partir do endereço eletrônico do Departamento de Informática do Sistema Único de Saúde (DATASUS), com acesso em 15 de agosto de 2020 e 23 de outubro de 2020. A partir dos dados extraídos, foram construídos gráficos e tabelas.

Foram analisadas as variáveis segundo o ano e região de notificação, o perfil das vítimas (sexo e faixa etária), e o caráter de atendimentos dos casos. Neste estudo, o termo "queimaduras" abrange todos os casos de queimaduras e corrosões.

\section{RESULTADOS}

Quanto à prevalência de queimaduras no período entre 2015 a 2019, no Brasil, o estudo obteve amostra de 127.190 casos. A amostra deste estudo inclui casos de notificações de queimaduras entre indivíduos de menos de 1 ano a 80 e mais anos de idade, de ambos os sexos e de todas as regiões do Brasil.

A análise da prevalência de queimaduras no decorrer do período analisado revela que o ano de 2015 obteve menor prevalência, enquanto o ano de 2019 resultou em maior prevalência de notificações. Percebese que houve um aumento no número de notificações a cada ano do estudo. A percentagem de notificações de queimaduras variou de $18,6 \%$ a $21,6 \%$ entre os anos do estudo (Gráfico 1). 
Gráfico 1 - Distribuição da percentagem de notificações de queimaduras, conforme $o$ ano de notificação, $n=127.190$, Brasil, 2019.

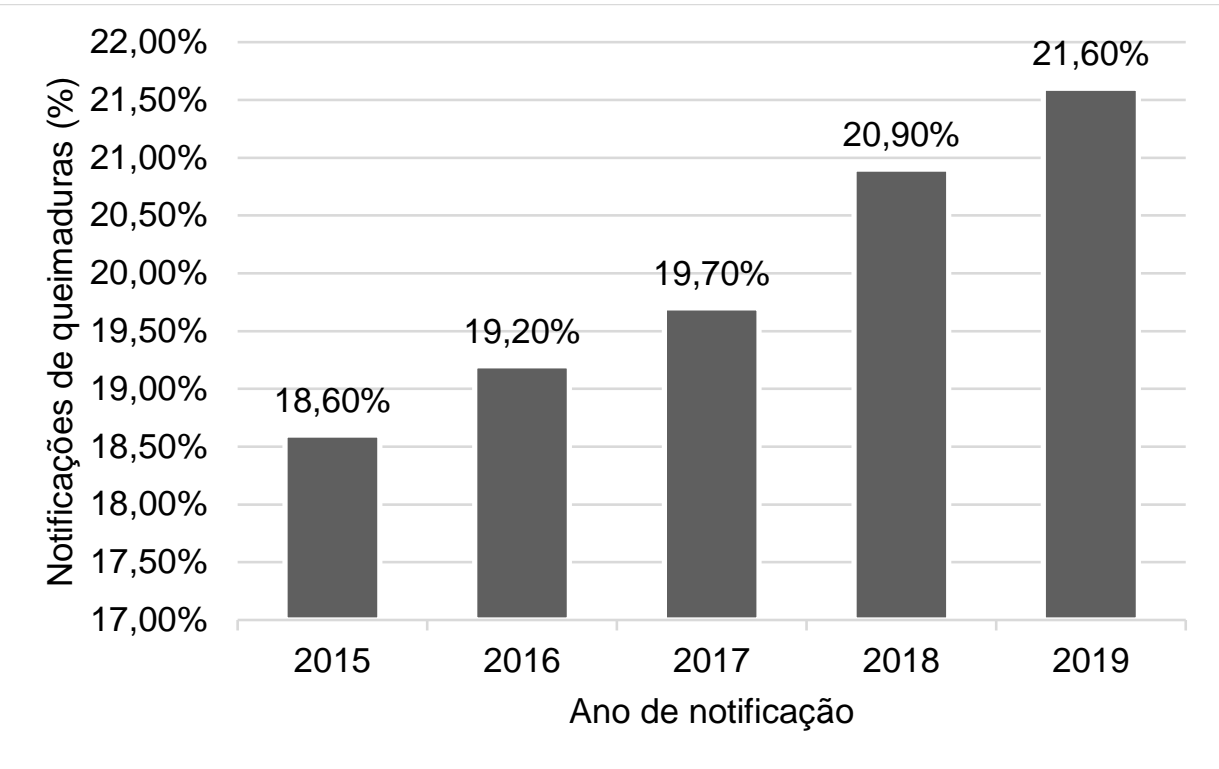

Fonte: OLIVEIRA RC, et al., 2020; dados extraídos do SIH-SUS/SVS/MS.

Em relação às regiões do Brasil, o Sudeste apresentou maior prevalência de notificações de queimaduras $(33,8 \%)$, seguido do Nordeste (28,7\%), Sul (18,4\%), Centro-Oeste $(13,0 \%)$ e, com menor prevalência, o Norte $(6,1 \%)$. É importante ressaltar a significativa diferença na quantidade de notificações de queimaduras nas regiões do Sudeste e Norte, visto que naquela a quantidade de notificações é cerca de cinco vezes maior quando comparada a esta (Gráfico 2).

Gráfico 2 - Distribuição da percentagem de notificações de queimaduras, conforme as regiões do Brasil, $n=127.190$, Brasil, 2019.

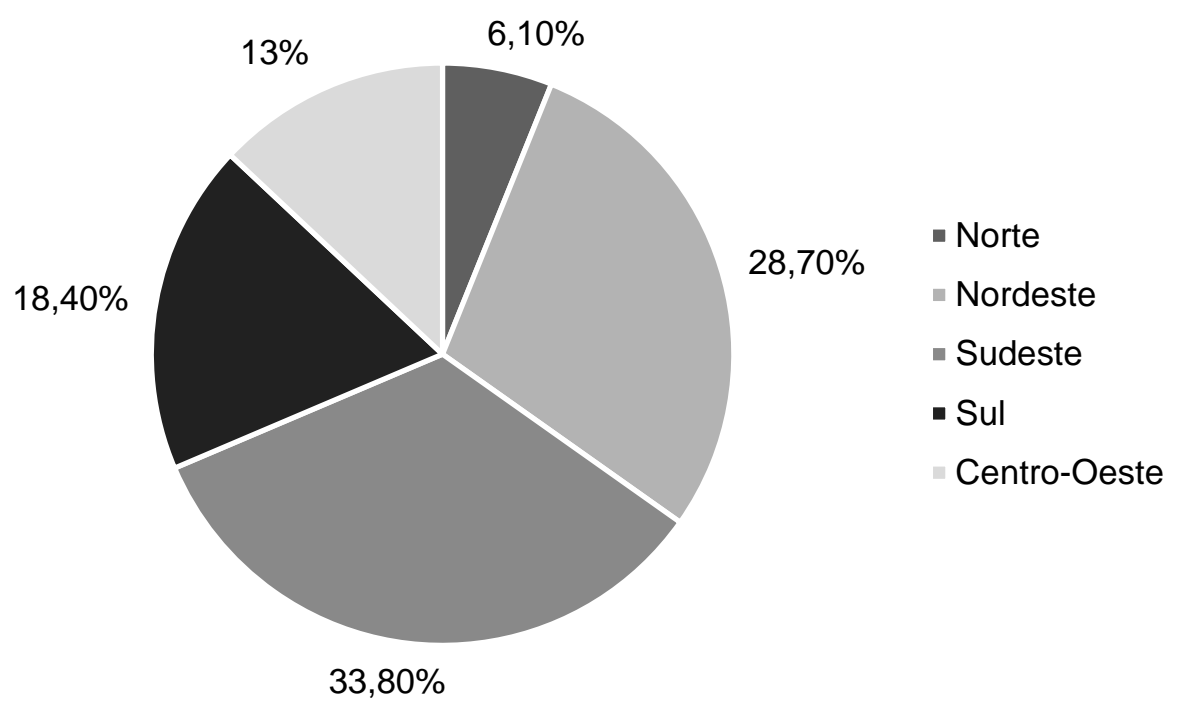

Fonte: OLIVEIRA RC, et al., 2020; dados extraídos do SIH-SUS/SVS/MS.

Correlacionando as notificações de queimaduras conforme o ano e regiões do Brasil, é possível observar que na maioria das regiões houve um aumento progressivo do número de notificações durante o período analisado. No ano de 2017, o Nordeste apresentou uma diminuição na prevalência de queimaduras, em comparação aos anos anteriores. Contudo, a partir do ano de 2018 , as notificações de queimaduras nesta região também apresentaram aumento progressivo (Gráfico 3). 
Gráfico 3 - Distribuição do número de notificações de queimaduras, conforme o ano de notificação e regiões do Brasil, $n=127.190$, Brasil, 2019.

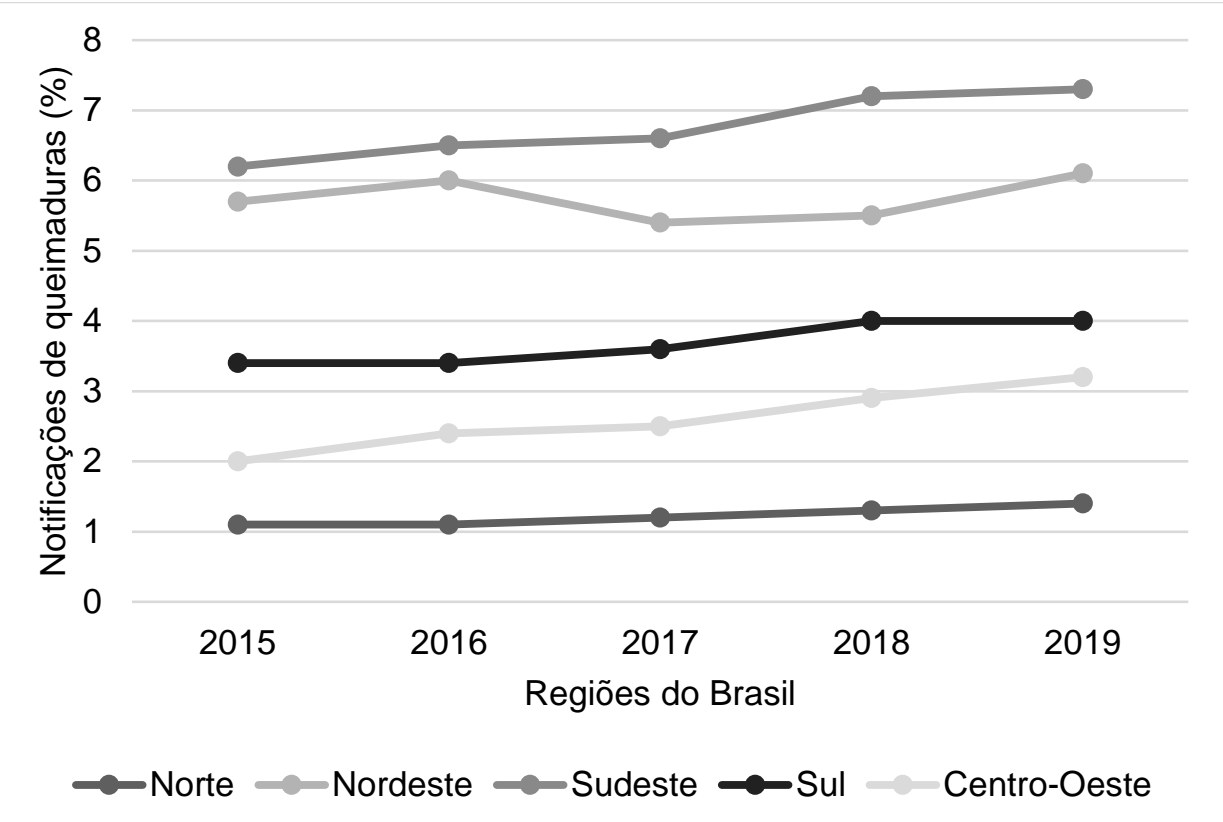

Fonte: OLIVEIRA RC, et al., 2020; dados extraídos do SIH-SUS/SVS/MS.

Em relação ao sexo, o masculino foi responsável por mais da metade dos casos de notificações por queimadura, com $63,2 \%$ dos casos. Quanto à faixa etária, houve prevalência de queimaduras em indivíduos de 20 a 39 anos, com $30,5 \%$ dos casos, seguido das faixas etárias de 1 a 4 anos e de 40 a 59 anos, com $18,0 \%$ e $22,5 \%$ dos casos, respectivamente. É importante observar que a faixa etária pediátrica, considerada entre os menores de 1 ano até 14 anos de idade, obteve prevalência de $32,4 \%$. A faixa etária de menor prevalência foi entre indivíduos com 80 e mais anos de idade, com 1,1\% dos casos. Considerando o caráter de atendimento, a maior parte foi de urgência, com $85,7 \%$ dos casos (Tabela 1).

Tabela 1 - Distribuição do número de notificações de queimaduras, conforme o sexo, faixa etária e caráter de atendimento, $n=127.190$, Brasil, 2019.

\begin{tabular}{ccc}
\hline Variável & $\mathbf{N}$ & $\%$ \\
\hline Sexo & & \\
\hline Masculino & 80.360 & 63,2 \\
Feminino & 46.830 & 36,8 \\
\hline Faixa etária & & 2,6 \\
\hline Menor de 1 ano & 3.301 & 18,0 \\
1 a 4 anos & 22.947 & 6,9 \\
5 a 9 anos & 8.846 & 4,9 \\
10 a 14 anos & 6.212 & 5,3 \\
15 a 19 anos & 6.637 & 30,5 \\
20 a 39 anos & 38.885 & 22,5 \\
40 a 59 anos & 28.535 & 8,2 \\
60 a 79 anos & 10.428 & 1,1 \\
80 anos e mais & 1.399 & 85,7 \\
\hline Caráter de atendimento & & 3,5 \\
\hline Urgência & 108.913 & 10,8 \\
\hline Eletivo & 4.591 & \\
lgnorado & 13.686 & \\
\hline
\end{tabular}

Fonte: OLIVEIRA RC, et al., 2020; dados extraídos do SIH-SUS/SVS/MS. 


\section{DISCUSSÃO}

Diante da facilidade e disponibilidade de acesso, este estudo optou pela coleta de dados e informações por meio do SIH-SUS. Considerando-se a obrigatoriedade das notificações de morbidades por causas externas no Brasil (o que inclui os eventos de causas acidentais, como as queimaduras), presume-se a veracidade dos dados coletados.

A análise das notificações de traumas por queimaduras, disponíveis no SIH-SUS, no período entre 2015 a 2019, revelou que o ano de 2019 obteve maior prevalência de casos de queimaduras, em oposição ao ano de 2015, com menor prevalência Estes dados demonstram a necessidade da implantação de medidas de prevenção às queimaduras no Brasil, visto que o número de casos relacionados a este agravo manteve-se em aumento progressivo durante cinco anos.

Quanto às regiões do Brasil, o estudo revelou um número significativo de notificações de queimaduras na região do Sudeste, Nordeste e Sul, que coincide com dados da literatura que destacam ambas as regiões como prevalentes em casos de queimaduras no Brasil (SILVA JAC, et al., 2015). Segundo dados do Instituto Brasileiro de Geografia e Estatística (IBGE), o Sudeste e Nordeste apresentam as maiores densidades demográficas do Brasil (BRASIL, 2019). Assim, a elevada concentração populacional nestas regiões pode justificar a maior prevalência de acidentes por queimaduras.

Cabe destacar que nas regiões Sul e Sudeste estão concentrados os maiores centros de tratamentos intensivos especializados em queimaduras do Brasil, o que também explica a maior prevalência de internações hospitalares nestas regiões, já que as vítimas de queimaduras podem são encaminhadas para tratamento nestas regiões (MESCHIAL WC, et al., 2016). Associado a isso, fatores relacionados à costumes regionais podem estar associados à maior prevalência de acidentes por queimaduras, como o caso das típicas festas juninas da região do Nordeste. $O$ uso de fogueiras e fogos de artifícios durante estas festividades, muitas vezes sem o uso de equipamentos de proteção adequados, podem gerar situações de risco e maior predisposição à acidentes (FERREIRA LLP, et al., 2019).

O estudo revelou a maior prevalência de queimaduras entre indivíduos do sexo masculino, o que corrobora com dados da literatura que associam os homens às ações de menor cautela, além de estarem mais vinculados às atividades laborativas associadas a maior risco de queimadura, como no uso de substâncias químicas e de serviços que envolvem a eletricidade e funções automobilísticas (SOARES LR, et al., 2016). Além disso, considerando a significativa prevalência da população pediátrica em traumas de queimaduras, a prevalência do sexo masculino pode se justificar também pelo elevado número de meninos vítimas de queimaduras. Estes costumam receber maior liberdade dos pais nas brincadeiras e atividades cotidianas, podendo este fator contribuir para maior exposição às situações de risco e, consequentemente, a acidentes que geram queimaduras (SIQUEIRA SMC, et al., 2017)

Em relação à faixa etária, houve um elevado número de notificações de queimadura entre indivíduos adultos-jovens, considerados entre 20 a 39 anos de idade. Neste grupo também há a associação de maior risco de queimaduras ocupacionais, já que esta faixa etária é representada por um maior número de indivíduos em atividades trabalhistas. Cabe ressaltar os prejuízos em âmbito socioeconômico decorrentes dos acidentes por neste este grupo, já que nessa faixa-etária concentra-se a maior parte da população economicamente ativa (CARDOSO L, et al., 2012). Novamente a epidemiologia das queimaduras despertam a atenção para a necessidade de implantação de campanhas de prevenção que visem a redução destes acidentes, buscando diminuir o impacto socioeconômico relacionado a este agravo à saúde.

O estudo mostrou um significativo número de notificações por queimaduras na faixa etária pediátrica, principalmente entre 1 a 4 anos. Especificamente neste período da vida inicia-se a fase de deambulação, além do surgimento de interesses em exploração do meio em que estas crianças vivem. Cabe ressaltar que os principais fatores de risco associados às queimaduras pediátricas são a idade inferior a 5 anos, o sexo masculino, o contato com líquidos aquecidos e o uso de álcool em ambiente doméstico. As medidas mais eficazes na redução de acidentes são as ações educativas no ambiente escolar e a divulgação de informações nos meios de comunicação (MESCHIAL WC, et al., 2016). 
A literatura demonstra que as principais causas de queimaduras pediátricas são em decorrência de acidentes por escaldaduras. Na maioria significativa dos casos, há evidências de que pelo menos um responsável pela criança estava presente no local do acidente. Estes acidentes ocorrem principalmente na cozinha e quintal de suas próprias casas. Habitações com aglomeração de pessoas, crianças não primogênitas e a mudança para uma nova residência são considerados fatores associados a maior risco de acidentes domésticos por queimaduras na faixa etária pediátrica (YODA CN, et al., 2013).

Quanto à faixa etária de idosos, o estudo demonstrou que a idade entre 60 a 79 anos está mais associada a notificações, havendo uma queda nos índices de queimaduras após a idade de 80 anos e mais. Estudos associam os acidentes de queimadura entre idosos à déficits sensoriais, funcionais e cognitivos, fatores estes que geram prejuízos nos mecanismos de proteção desta população. Ainda, as queimaduras em idosos apresentam evolução clínica mais desfavorável, resultando muitas vezes em longos períodos de internação hospitalar e recuperação clínica lenta (GIULI AE, et al., 2015).

Em relação ao caráter de atendimento, os atendimentos de urgência foram os mais prevalentes, o que corrobora com dados da literatura (MALTA DC, et al., 2020). O atendimento de pacientes queimados em unidades de saúde deve basear-se no suporte básico de vida, com ênfase na proteção e permeabilidade de vias aéreas, e na assistência ventilatória e circulatória (BRASIL, 2012). Assim, é fundamental a preparação de profissionais de saúde nos serviços de urgência e emergência para o adequado manejo dos traumas por queimaduras.

As vítimas que sofrem lesões inalatórias em acidentes com fogo podem necessitar de suporte respiratório na urgência (BRASIL, 2012). Nos serviços de urgência é fundamental a realização do controle da função respiratória dos acidentados, que pode ser realizado através do uso de cateter nasal ou, em casos mais graves, da intubação orotraqueal. $O$ exame das vias aéreas superiores e da traqueia que revelam edema, eritema, ulceração e presença de fuligem, indicam a possibilidade de lesões inalatórias. Queimaduras de face, estridor, desconforto respiratório, sibilância, tosse produtiva e dispneia também podem indicar a presença de lesões por inalação (SILVEIRA RC, et al., 2017).

Ainda, as perdas plasmáticas de pacientes queimados aumentam o risco do desenvolvimento de choque hipovolêmico. O adequado manejo do controle hemodinâmico e da reposição volêmica permitem uma melhor evolução e prognóstico dos pacientes queimados. A correta avaliação da superfície corporal queimada por meio da regra de Wallace é imprescindível no cálculo da reposição de volume a ser administrada nestes pacientes (CUNHA LVT, et al., 2016).

Com menor prevalência, os atendimentos eletivos são voltados principalmente às queimaduras de primeiro grau. Nestes casos, o manejo dos pacientes baseia-se principalmente nos cuidados gerais da área queimada e no controle da dor. Recomenda-se aos pacientes que mantenham um ambiente higienizado e úmido no local da lesão, objetivando a aceleração do processo de epitelização (BRASIL, 2012).

O SIH-SUS não apresenta dados quanto à evolução dos casos de queimaduras. Dessa forma, não foi possível a determinação do índice de mortalidade relacionado aos traumas por queimaduras. No Brasil, cerca de 3 a 5\% das vítimas internadas por queimaduras evoluem para óbito (BARCELLOS LG, et al., 2018). A mortalidade por queimaduras está associada principalmente ao choque séptico e à disfunção orgânica, consideradas consequências tardias das lesões por queimaduras (JUNIOR RAS, et al., 2016; MARINHO LP, et al., 2018).

Cabe ressaltar que, apesar de menos frequentes, as queimaduras causadas por tentativa de autoextermínio são um fenômeno que carece atenção, dado a sua gravidade. Pacientes com queimaduras por autolesão costumam permanecer em internação hospitalar por mais tempo, possuem mais complicações infecciosas e maior taxa de letalidade, quando comparados às vítimas de acidentes por queimaduras.

Este tipo de evento é mais comum em mulheres, na faixa etária entre 20 a 40 anos (MACEDO JLS, et al., 2011; MIRESKI R, et al., 2016). Não foi possível especificar neste estudo a quantidade de casos de queimaduras decorrentes de lesão por autoextermínio, em decorrência da limitação de dados fornecidos no SIH-SUS. 
Devido à utilização de dados secundários, torna-se fundamental destacar a possibilidade de limitações neste estudo, sobretudo relacionadas a falhas na coleta de dados e registros das notificações de queimaduras. Além disso, percebe-se que os dados fornecidos no SIH-SUS não abrangem elementos importantes para a avaliação epidemiológica, como grau, extensão e gravidade das lesões; agente causal e evolução dos casos. Assim, sugere-se o aprimoramento do serviço de notificações de queimaduras no Brasil, com a disponibilização de itens na ficha de notificação que permitam um melhor detalhamento dos acidentes. Apesar disso, acredita-se que os resultados deste estudo alcançaram os objetivos propostos, caracterizando a epidemiologia dos traumas por queimaduras no Brasil.

Por último, destaca-se a importância de medidas voltadas à diminuição dos traumas por queimaduras, principalmente aos grupos de risco. A oferta de equipamentos de proteção e a orientação de medidas de segurança podem reduzir a prevalência de queimaduras relacionadas à acidentes de trabalho. $A$ instrução no cuidado às crianças, visando a prevenção de acidentes domésticos, é imprescindível na mudança do perfil epidemiológico das queimaduras pediátricas. Além disso, a orientação e execução de atitudes que proporcionem ambientes seguros e a capacitação de cuidadores para melhor acompanhamento do idosos também podem auxiliar na redução de queimaduras nesta população. A ampliação de informações de prevenção às queimaduras pode ser ofertada através de meios de comunicação na mídia, de ações na atenção primária à saúde e de medidas educativas em ambientes escolares.

\section{CONCLUSÃO}

Através deste estudo foi possível caracterizar a epidemiologia dos traumas por queimaduras no Brasil. Observou-se a necessidade da ampliação de medidas preventivas voltadas às queimaduras, tendo em vista 0 aumento progressivo da prevalência de acidentes durante o período avaliado no estudo. As regiões Sudestes e Nordeste apresentaram os maiores índices de internações por queimaduras, possivelmente em virtude da elevada densidade demográfica nestas regiões. Quanto ao perfil das vítimas, adultos-jovens e crianças, principalmente do sexo masculino, compõem o principal grupo de risco para traumas por queimaduras. Apesar de apresentar menor prevalência de notificações, os idosos representam um grupo de elevado risco para a mortalidade por queimaduras, tendo em vista as possíveis comorbidades e debilidades já associadas. O caráter de atendimento urgente foi o prevalente neste estudo. Ressalta-se a imprescindível necessidade de ampliação de esforços em ações educativas que visam prevenir acidentes de queimaduras, enfatizando principalmente os grupos de maior risco.

\section{REFERÊNCIAS}

1. BARBOSA GS, et al. Características clínicas e fatores associados aos óbitos de indivíduos queimados em um Centro de Referência de Ananindeua-PA. Revista Brasileira Queimaduras, 2016; 15(2): 104-109.

2. BARCELLOS LG, et al. Características e evolução de pacientes queimados admitidos em unidade de terapia intensiva pediátrica. Revista Brasileira Terapia Intensiva, 2018; 30(3): 333-337.

3. BRASIL. Instituto Brasileiro de Geografia e Estatística. Síntese de indicadores sociais: uma análise das condições de vida da população brasileira: 2019. Rio de Janeiro, 2019.

4. BRASIL. Ministério da Saúde. Cartilha para tratamento de emergência das queimaduras. Brasília, 2012.

5. CAMPOS ALS, et al. Estresse parental em mães de bebês, crianças e adolescentes com queimadura. Revista Brasileira de Queimaduras, 2016; 15(4):240-245.

6. CARDOSO L, et al. Estudo epidemiológico das queimaduras químicas dos últimos 10 anos do CTQ-Sorocaba/SP. Revista Brasileira de Queimaduras, 2012; 11(2): 74-79.

7. CHAVES SCS. Ações da enfermagem para reduzir os riscos de infecção em grande queimado no CTI. Revista Brasileira de Queimaduras, 2013; 12(3): 140-144.

8. COUTINHO JGV, et al. Estudo de incidência de sepse e fatores prognósticos em pacientes queimados. Revista Brasileira de Queimaduras, 2015; 14 (3): 193-197.

9. CRUZ BF, et al. Perfil epidemiológico de pacientes que sofreram queimaduras no Brasil: revisão de literatura. Revista Brasileira de Queimaduras, 2012; 11(4): 246-250.

10. CUNHA LVT, et al. Atendimento inicial ao paciente queimado: avaliação do conhecimento de alunos do internato do curso de Medicina. Revista Brasileira de Queimaduras, 2016; 15(2): 80-86.

11. FERNANDES FMFA, et al. Queimaduras em crianças e adolescentes: caracterização clínica e epidemiológica. Revista Gaúcha Enfermagem, 2012; 33(4): 133-141.

12. FERREIRA LLP, et al. Perfil epidemiológico dos pacientes vítimas de queimaduras no estado da Bahia no período de 2009 a 2018. Revista Brasileira de Queimaduras, 2019; 18(1): 33-8. 
13. GIULI AE, et al. Caracterização de idosos vítimas de queimaduras internados em um centro de tratamento de queimados. Revista Brasileira de Queimaduras, 2015; 14(4): 253-256.

14. GUIMARÃES CE, et al. Epidemiologia das queimaduras no estado de Minas Gerais. Revista Brasileira Cirurgia Plástica, 2011; 26(4): 573-577.

15. GONÇALVES N, et al. Fatores biopsicossociais que interferem na reabilitação de vítimas de queimaduras: revisão integrativa da literatura. Revista Latino-Americana de Enfermagem, 2011; 19(3): 1-9.

16. JUNIOR RAS, et al. Perfil epidemiológico dos pacientes queimados no Hospital de Urgências de Sergipe. Revista Brasileira de Queimaduras, 2016; 15(4): 251-255.

17. LOPES DR, et al. Associação de membrana biológica de hemicelulose com pomada de estimulação da epitelização: Relato de caso. Revista Brasileira de Queimaduras, 2016; 15(4): 283-286.

18. MACEDO JLS, et al. Queimaduras autoinfligidas: tentativa de suicídio. Revista Colégio Brasileiro de Cirurgia, 2011; 38(6): 387-391.

19. MALTA DC, et al. Perfil dos casos de queimadura atendidos em serviços hospitalares de urgência e emergência nas capitais brasileiras em 2017. Revista Brasileira de Epidemiologia, 2020; 23: E200005, Supl.1.

20. MARINHO LP, et al. Perfil epidemiológico de vítimas de queimadura internadas em hospital de trauma na região Norte do Brasil. Revista Brasileira de Queimaduras, 2018; 17(1): 28-33.

21. MESCHIAL WC, et al. Fatores de risco e medidas de prevenção das queimaduras infantis: revisão integrativa da literatura. Revista Brasileira de Queimaduras, 2016; 15(4): 267-273.

22. MIRESKI R. Queimaduras por tentativa de suicídio e homicídio e a sua associação com o prognóstico Revista Brasileira de Queimaduras, 2016; 15(2): 87-91.

23. SILVA JAC, et al. Perfil dos pacientes atendidos por queimaduras em um hospital de referência no norte do Brasil. Revista Brasileira de Queimaduras, 2015; 14(3): 197-202.

24. SILVEIRA RC, et al. Perfil epidemiológico dos pacientes com lesão inalatória que foram atendidos em uma Unidade de Queimados de um Hospital de Pronto-Socorro. Revista Brasileira de Queimaduras, 2017; 16(3): 150-156.

25. SIQUEIRA SMC, et al. Internações e óbitos de crianças e adolescentes brasileiros vítimas de queimaduras por fogos de artifício. Revista Brasileira de Queimaduras, 2017; 16(2): 68-75.

26. SOARES LR, et al., Estudo epidemiológico de vítimas de queimaduras internadas em um hospital de urgência da Bahia. Revista Brasileira de Queimaduras, 2016; 15(3): 148-152.

27. YODA CM, et al. Queimadura pediátrica: fatores associados a sequelas físicas em crianças queimadas atendidas no Hospital Infantil Joana de Gusmão. Revista Brasileira de Queimaduras, 2013; 12(2): 112-117. 